
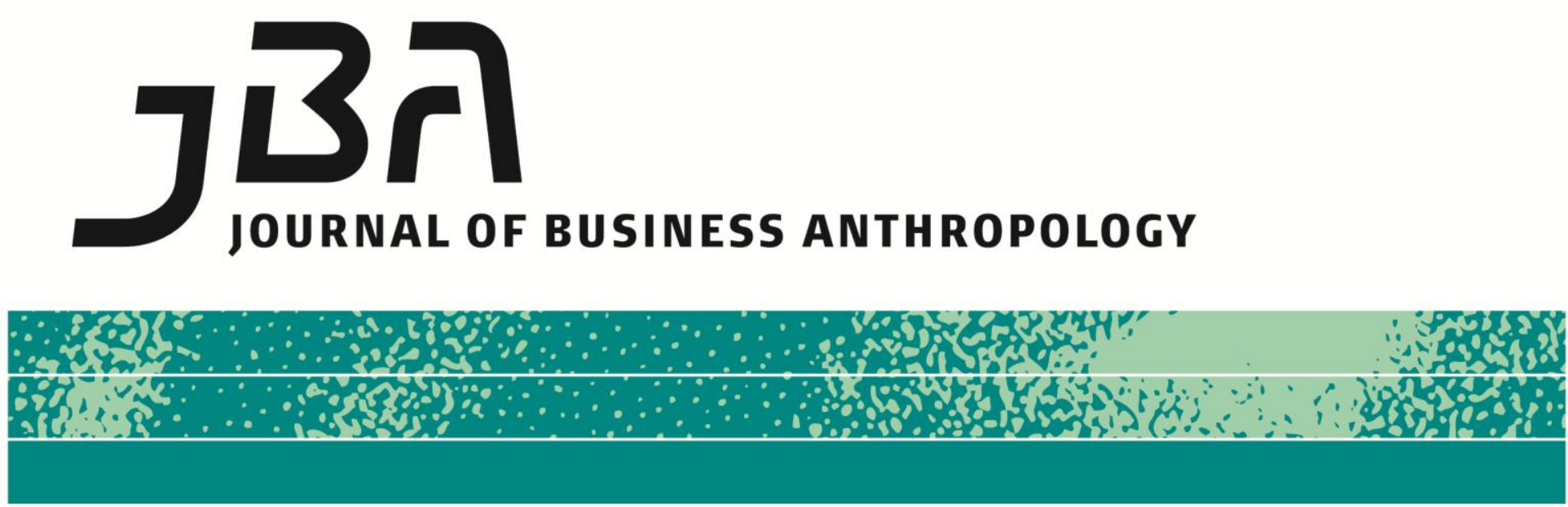

\title{
Just Be Active! Letter from Your Editor
}

\author{
Brian Moeran
}

Well, here we are again. The fourth issue of the $J B A$ heralds the end of this journal's second year in existence - not bad, really, given the fact that most journals, like most new products, tend to disappear from the supermarket shelf of academic ideas after a few issues. It's always good to buck a trend.

Still, the question remains lurking in the background, as I move forward with the fifth issue due out next spring: how long will the JBA continue? Or rather, how long should it, how long does it need to, continue? By this I mean that any new academic journal, when launched, should set itself a specific task (to explore a new field of research, for example, or to bring together scholars from across disciplinary boundaries) and keep that task in mind throughout its early years. Once it has achieved that task, it should either set itself a new task, or gracefully retire from the unholy realm of journal rankings, impact factors, and hindices.

So, what tasks did we have in mind for the $J B A$ when Christina Garsten and I launched it in the spring of 2012? Well, first and foremost, the idea was to provide a forum for those involved in one way or another in business anthropology to write about methodological, theoretical, and practical challenges that they faced in their research and/or working environments. In this way, secondly, we hoped that this forum might be read by and influence people actually engaged in business of all kinds, and that, as a result, the discipline of anthropology might be regarded not just
Page 1 of 5

JBA 2(2): 115-119 Fall 2013

(C) The Author(s) 2013 ISSN 2245-4217

www.cbs.dk/jba 
as an ethnographic fad, but as a serious analytical tool that could help business organizations in one way or another.

At the same time, thirdly, we wanted to bring together the slightly differently-focused North American and European (but also Japanese and Chinese) strands and traditions of 'business', 'corporate', 'enterprise', 'organizational' and 'administrative' anthropologies, so that each might learn from the others. And fourthly, by providing such a forum, we aimed more generally to highlight through publication of the JBA the existence of a 'business', as opposed to some other kind of (cognitive, development, feminist, media and so on), anthropology. In this respect, we sought to engage in a dialogue with the discipline as a whole.

In other words, the $J B A^{\prime}$ 's main task has been two-fold: to engage with people employed in business activities, on the one hand, and with academic mainstream anthropologists, on the other. The question then becomes: how successful has the JBA been in carrying out these tasks?

Let me start with mainstream anthropologists. I think it fair to say that there has been a slight shift in their thinking about the world of business over the past decade - primarily, perhaps, thanks to the efforts of anthropologists both in and outside academia who have been analysing the financial world (Melissa Fisher, Karen Ho, Douglas Holmes, Hirokazu Miyazaki, Annelise Riles, Gillian Tett, and Caitlin Zaloom among many) and that the $J B A$ has been able to take advantage of this. Nevertheless, I also think it fair to say that there still exists a hard-core group of anthropologists who read the anthropology of finance writings because they confirm their anti-capitalist leanings (and I have to say that I don't entirely blame them for this as people; the problem is when, as anthropologists, they express such leanings in unfounded biases).

In this respect, I feel it necessary to remind my mainstream colleagues that the $J B A$ is designed to make all anthropologists aware of the following issues:

1. Firstly, that there is probably not a single aspect of 'culture' in contemporary societies that has not in some way been commercialized. This fact should not just be deplored, but analysed;

2. 'Business' involves the trade of technologies, products, social and cultural processes, people, money, and ideas (Arjun Appadurai's notion of 'scapes'). As a result, anthropologists ignore business at their peril; and thirdly,

3. It is somewhat dishonest, isn't it, for anthropologists to look down upon and ignore anything connected with commerce? Putting aside who pays us to do what we do, we should remember that our discipline, by its very nature, does not recognize an absolute hierarchy of categories. In this, some anthropologists seem as misguided (and self-righteous) as 
painters, perfumers and porcelain potters who believe in the 'purity' of their art, 'unsullied' by money.

All of this strikes me as so obvious that it hardly needs saying. But this 'transparency' also means that the initial tasks of the $J B A$ with regard to mainstream anthropology should be accomplished within a fairly short time - no more than a decade, at most. In which case, either a peripheral sub-discipline of anthropology will have moved centre-stage, or the core discipline will have finally learned how to walk (or maybe just crawl) towards the edge of its hitherto blinkered horizons. As a result there will be no further need for a journal devoted specifically to business anthropology since all anthropology publications will be taking the importance of business in social and cultural affairs for granted and incorporating it in their analyses.

Wishful thinking? Maybe, although I hope not (your Editor is, after all, not immortal!). Which brings me to the second half of the twofold objective outlined above: reaching out to the business world. Here Patricia Sunderland and Rita Denny are also purveyors of hope. In their opinion piece in this issue, they describe how a client for whom they were working behaved just like an anthropologist as he made suggestions and advised them about the project to hand. Their unanticipated conclusion from this particular project is that perhaps - just perhaps - the world of business is beginning to take note, and approve, of anthropology as a right, proper and effective means of understanding business corporations, practices, ethics, and so on. But this realization comes from a single example of anthropologists working with their business client. What is needed are more case studies, more instances of such cooperation between anthropologists and business people.

And this is where you, the silent majority of readers of the $J B A$, really do need to act.

The action that I'm inviting of you should be on two fronts. Firstly, are business people reading the $J B A$ and, if so, what do they think of it? Are its articles, essays, case studies, field reports, and opinion pieces of any interest or use to those in the trenches? What works and what doesn't, and why (not)?

Secondly, one of the paradoxes of launching a journal of business anthropology is that the $J B A$ has received a lot of support from those working as anthropologists in, for, with (and even against) business organizations of one sort or another. And yet it is precisely these business anthropologists who have in very large part not contributed voluntarily to the $J B A$. Instead, article submissions have mostly been coming from scholars employed in universities, business schools, and other institutions of higher education - mainly in Europe. This may, of course, have something to do with the European location of the JBA's editors. But I suspect that a lot more is connected with the fact that business anthropologists who are not employed in universities and so on either 
don't think they have the time or perseverance to write intelligent - a word that I prefer to 'scholarly' - articles, or are concerned about issues of client confidentiality that reduce them to silence.

I don't know, though, because none of you says anything! Isn't it time you made your voices heard?

This issue starts off with an essay by James Carrier about business literature. It is, specifically, an essay - not an article - intended to lay out a few ideas and inviting responses from its readers. So, please, do think about what James has written and come back to me with your own longer or shorter essays about your takes on business literature. I would like to be able to publish them in the next issue of the JBA.

And then there are the articles, each of them concerned with particular aspects of fieldwork experiences, and each crying out for discussion and debate. So, again, I call upon you to engage with the issues that these authors raise, and write in with your own takes on the following:

- Machteld de Jong, Frans Kamsteeg, and Sierk Ybema direct our attention towards the idea of 'defamiliarization' that comes into fieldwork, but which is rarely discussed. They suggest six estrangement strategies (three theoretical and three methodological) that allow the researcher to develop a more detached viewpoint from which to interpret data. What do you think of these strategies? Do you have similar examples of such strategies from your own fieldwork experiences? Can you suggest other strategies?

- With remarkable frankness, Ghislaine Gallenga outlines the different strategies and roles she adopted, or was obliged to adopt, in three different fieldwork situations where she was caught up in power struggles of one kind or another. What would you have done in similar situations? Would you have opted to go 'undercover' in one fieldwork site, or join a strike in another? How should an ethnographer deal with power when 'studying up' (down, sideways, through, backwards, forwards, and so on)?

- Lotta Björklund Larsen asks how an ethnographer should deal with knowledge production within a governmental (or business) organization whose employees read, and also learn from, what he or she writes. This is implicit, too, in Katarina Graffman's opinion piece where she distinguishes between 'academic' and 'business' forms of writing and presentation. What are your experiences in this regard? What forms should the JBA itself adopt?

- At the beginning of her article, Benedicte Brøgger outlines three types of research on culture in entrepreneurship. The first of these, how culture produces entrepreneurship, introduces the work of Dutch management scholar and self-appointed anthropologist, 
Geert Hofstede. (Do I hear a confused query: 'Geertz who?'!) Given the enormous importance attributed to the work of Hofstede in business schools around the world, and given, therefore, his corresponding influence on business people's apprehension and comprehension of 'anthropology' as an intellectual discipline, it is time for business anthropologists to engage seriously with his work and methods. Are there some of you out there who might want to do this? Can you write in with an outline of the main tenets of Hofstede's work, and methodology, plus praise or critique thereof in the context of its role in the worlds of business and business schools? Can you situate his work in business anthropology as you yourselves understand and practise it?

By now you will have realised that there is another task that the $J B A$ has set itself: reader engagement. Let's face it, there is nothing worse for an editor than to publish a journal that may be very highly respected, but whose articles are read by no more than a handful - OK, two handfuls - of scholars around the world. Fortunately, download statistics suggest that articles in the JBA are being read by thousands. This is phenomenal and makes the horrendous task of editing a journal totally worthwhile. What I want to know, however, is what these thousands think of the journal and the theoretical, methodological and practical issues its articles and opinion pieces raise. As Editor, I need feedback from you to make sure that I can continue to attract your interest and goodwill. So please do start writing. And, if in doubt, remember: from now on the acronym $J B A$ also stands for:

Just Be Active! 